\title{
AS HUMANIDADES EM TEMPOS DE NEOLIBERALISMO: O MODUS OPERANDI DE DUAS UNIVERSIDADES JESUITAS NA AMÉRICA LATINA
}

\author{
João Batista Storck* \\ lattes.cnpq.br/9411371632646979
}

\begin{abstract}
Resumo: O artigo analisa o modus operandi de duas universidades jesuítas na América Latina - a Pontificia Universidad Javeriana, na Colômbia, e a Universidade do Vale do Rio dos Sinos (Unisinos), no Brasil - no atual contexto do neoliberalismo econômico, que possui como centro de interesse as questões econômicas, sendo que essas instituições por pertencerem à Companhia de Jesus, ordem religiosa que estruturou a sua área educacional a partir dos princípios do humanismo cristão, possuem como centro de convergência a pessoa humana. Foram analisados: O Estatuto 2014, o Plano de Desenvolvimento Institucional e o Projeto Pedagógico Institucional 20062011 da Unisinos e, o Estatuto 2013, a Planeación Universitaria 2007-2016, e o Proyecto Educativo 1992-2015 da Javeriana. Como referencial teórico-metodológico utilizou-se a ideia de Triangulação Metodológica composta pela 'Abordagem do Ciclo de Políticas' de Stephen J. Ball; o Método da Análise Documental de André Cellard e, o Método Comparado em Educação de George Z.F Bereday. Destacam-se como principais resultados, dentre outros, o fato de que os respectivos documentos foram elaborados a partir de uma complexa mescla de orientações e regulamentos provenientes da Igreja Católica, da Companhia de Jesus, das legislações colombiana e brasileira, influenciadas na sua elaboração pelos documentos dos organismos internacionais portadores da lógica neoliberal (UNESCO e Banco Mundial) e, o fato de que estas Universidades buscam conjugar o humanismo social cristão com a tecnociência, buscando a fidelidade aos seus princípios institucionais.
\end{abstract}

Palavras-chave: Universidades Jesuítas; Instituições de Educação Superior; Plano de Desenvolvimento Institucional; Projeto Pedagógico Institucional; Companhia de Jesus.

\section{HUMANITIES IN TIMES OF NEOLIBERALISM: THE MODUS OPERANDIS OF TWO JESUIT UNIVERSITIES IN LATIN AMERICA}

\footnotetext{
* Doutor em Educação pela Universidade do Vale do Rio dos Sinos, Unisinos (Brasil). Contato: jbssj@hotmail.com.
} 


\begin{abstract}
The present article analyzes the modus operandi of two Jesuit universities in Latin America - Pontificia Universidad Javeriana, Colombia, and University of Rio dos Sinos Valley (Unisinos), Brazil - in the current context of economic neoliberalism, that has as its core values economic issues, given that these institutions, as part of the Society of Jesus, a religious order that has structured its education area from the principles of the Christian Humanism, have the human person as their converging center. We have analyzed the following documents: the 2014 Statutes, the Institutional Development Plan and the Institutional Pedagogical Project 2006-2011 of Unisinos and the 2013 Statutes, the Planeación Universitaria 2007-2016, and the Proyecto Educativo 1992-2015 of Javeriana. As theoretical-methodological background, we have employed the idea of Methodological Triangulation formed by the Policy Cycle Approach by Stephen J. Ball; the Document Analysis Method by André Cellard and the Comparative Method in Education by George Z.F Bereday. Among our main findings we highlight the fact that these documents were drafted based on a complex mix of guidelines and regulations from the Roman Catholic Church, the Society of Jesus, the Colombian and Brazilian laws, influenced in their elaboration by papers from international bodies bearing the neoliberal logic (Unesco and World Bank) and the fact that those universities seek to combine Christian Social Humanism with technoscience, seeking fidelity to their institutional principles.
\end{abstract}

Keywords: Jesuit Universities; Higher Education Institutions; Institutional Development Plan; Institutional Pedagogical Project; Society of Jesus.

\title{
Introdução ${ }^{1}$
}

As universidades da Companhia de Jesus originaram-se com a Ordem em 1540, no auge do humanismo renascentista e cristão no século XVI, num complexo e efervescente contexto histórico, político, social, econômico e cultural que possuía como centro de interesse a pessoa humana, próprio dessa época. Quase cinco séculos se passaram e as universidades da Companhia de Jesus estão presentes em todo o mundo, em novos e diferentes contextos. Muitas dessas universidades estão na Amé-

\footnotetext{
1 Parte das reflexões e análises apresentadas neste artigo são decorrentes da pesquisa de doutorado em Educação do autor: "As humanidades em tempos de neoliberalismo em duas universidades latino-americanas" (Universidade do Vale do Rio dos Sinos Unisinos, 2016).
} 
rica Latina que vêm recebendo, nas últimas décadas, o impacto do modelo econômico neoliberal, cujo centro de convergência é as questões econômicas, afetando diferentes áreas das sociedades, entre elas a educação superior, atingindo várias instituições educacionais, entre as quais as da Companhia de Jesus. (BALL, 2012; CUNHA, 2011; DIDRIKSON, 2008; TEODORO, 2011).

Desde o início de sua fundação a Companhia de Jesus foi identificada pelo trabalho na área educacional, fundando colégios e universidades, passando por sucessos e insucessos, aprovação e críticas severas, simpatias e antipatias, seja por alguns segmentos da sociedade, seja da própria Igreja institucional e hierárquica. No entanto, a Ordem vem demonstrando ser capaz de gerenciar crises, tensões e de superar desafios, buscando adaptar-se aos novos tempos como mostra a sua história.

Os primeiros jesuítas, ao assumirem o humanismo tal como se definia no século XVI para evangelizar através da educação, assumiram riscos e consequências. Em primeiro lugar, essa opção supôs uma profunda abertura de espírito para aceitar que os clássicos e, os que não eram cristãos, tinham muito a ensinar para a compreensão cabal da doutrina cristã de então. Crer que ninguém, e nada, por mais longe que estivesse da verdade, deixava de ter algo da verdade, era algo fundamental para os jesuítas. A segunda consequência, advinda do fato de encarnar o cristianismo no humanismo, ou, assumir o humanismo grego latino com os ensinamentos filosóficos, morais e estéticos da antiguidade, foi o reconhecimento por parte dos jesuítas, que a genuína evangelização através da educação não se limitava ao estritamente religioso, mas compreendia a formação integral, a formação cívica e política, estética, literária e moral. O humanista não poderia ser somente um conhecedor da religião, mas deveria ter uma visão capaz de assumir as outras dimensões do saber e da existência humana. (MIRANDA, 2001).

Passados quase 500 anos, o humanismo cristão renascentista, um dos fatores que inspirou e constituiu a forma de educar da Companhia de Jesus, vem assumindo novos contornos e expressões, em outros contextos históricos, políticos, sociais, econômicos e culturais, especialmente após o advento da modernidade, sendo que na segunda metade do século 
passado, assistimos a três transições históricas que se catalisaram com o fim da chamada guerra fria: a revolução tecnológica, a globalização econômica e a globalização da informática comunicacional e da cultura.

Todas essas transições foram potencializadas a partir da década de 1970, pelo modelo econômico neoliberal, que tem modificado drasticamente a forma de viver de milhões de pessoas em todo o mundo, impactando profundamente o continente latino-americano. Estes fatos, quase simultâneos, produziram uma mudança de época mais que uma época de mudanças. A complexidade, as incertezas causadas por mudanças tão profundas e aceleradas, têm impactado e levado um sério questionamento às universidades em geral, e provocado uma redefinição de suas funções. $\mathrm{O}$ ethos cultural no passado tinha suas raízes definidas em um tipo de trabalho específico, dentro de um marco cultural-religioso de valores localizados em uma comunidade particular. A universidade era parte deste ethos cultural. A mudança de época tem transformado também o paradigma deste ethos cultural e, consequentemente, impactado as universidades de modo geral, enquanto entidades situadas na sociedade. As 31 universidades jesuítas na América Latina não ficaram imunes a esse impacto.

Do contexto apresentado, surgiram as seguintes questões que instigaram o desenvolvimento da pesquisa: 1) Quais elementos ou fatores inspiraram/influenciaram a elaboração das propostas educacionais da Universidade do Vale do Rio dos Sinos (Unisinos) e da Pontificia Universidad Javeriana (PUJ), pertencentes à Companhia de Jesus, ordem religiosa cuja característica principal é ter se estruturado desde as suas origens, assim como a sua área educacional, a partir dos valores e princípios do humanismo cristão, cujo centro de interesse e convergência é o ser humano, frente ao contexto neoliberal na América Latina, cujo centro convergente é as questões econômicas? 2) Essas universidades mantêm, e de que maneira, a fidelidade aos princípios humanísticos na elaboração dos seus documentos institucionais que expressam as suas propostas educacionais?

Considerando as questões apresentadas, o objetivo geral da pesquisa é mostrar quais os fatores e a maneira como os mesmos subsidiaram na 
elaboração dos seguintes documentos institucionais: o Estatuto 2014, o Plano de Desenvolvimento Institucional (PDI) e o Projeto Pedagógico Institucional (PPI) 2006-2011, da Unisinos, e o Estatuto 2013 a Planeación Universitaria (PU-2007-2016), e o Proyecto Educativo (PE) (1992-2015) da Pontificia Universidad Javeriana, documentos esses, que mostram o modus operandi dessas instituições. Os objetivos específicos são: fornecer subsídios à área de gestão dessas e de outras Instituições de Educação Superior (IES) para que as mesmas percebam quais os fatores influenciaram/inspiraram na elaboração das suas propostas educacionais; identificar e fornecer elementos a partir da análise dos documentos institucionais para que as instituições pesquisadas possam ver a si mesmas, considerando se as propostas educacionais expressas nos documentos institucionais são coerentes com os princípios humanísticos presentes na gênese constitutiva das mesmas; apresentar o modus operandi da área educacional da Companhia de Jesus no contexto latino-americano atual. Ou seja, mostrar a maneira como a Ordem que se caracteriza pela educação, atualiza as suas políticas e propostas educacionais humanistas frente aos desafios do mundo atual, permeado pelos valores econômicos neoliberais e a tecnociência.

\section{Fundamentação \\ teórico-metodológica}

A pesquisa se enquadra na perspectiva da abordagem qualitativa em educação. O método qualitativo possui um amplo campo disciplinar que abarca as ciências humanas e sociais, assumindo tradições ou paradigmas múltiplos de análises, provenientes tanto da fenomenologia, quanto do positivismo, do marxismo, da hermenêutica, da teoria crítica ou do construtivismo.

As estratégias de abordagem do objeto empírico se fundamentam na ideia de 'Triangulação Metodológica' discutida na literatura sobre metodologia da pesquisa. Segundo Duarte (2009, p. 11), "A triangulação seria uma forma de combinar metodologias em uma investigação e refere-se à com- 
binação de vários métodos qualitativos entre si ou à articulação entre métodos quantitativos e qualitativos”. Por isso, utilizou-se na pesquisa como referencial teórico-metodológico, a Abordagem do Ciclo de Políticas formulada pelo sociólogo inglês Stephen J. Ball e seu colaborador Richard Bowe (1994, 1998, 2006, 2012); o Método de Análise Documental proposto por Cellard (2012) e o Método Comparado em Educação de Bereday (1972). Estes métodos foram os mais adequados, pois atendem ao propósito da pesquisa, qual seja, desenvolver um conhecimento em relação às Universidades pesquisadas a partir dos seus documentos institucionais.

O referencial teórico e metodológico de Ball (1994, 1998, 2006, 2012) denominado Abordagem do Ciclo de Políticas, se trata ao mesmo tempo de um modelo teórico e de uma metodologia de análise que permite interpretar as políticas, como essas são articuladas e como ocorrem. Além disso, considerando o fato de que as políticas, compreendidas em sua complexidade e caracterizadas por elementos instáveis e contraditórios estão em permanente movimento, através do tempo e do espaço, possuindo certo grau de incerteza, sendo recontextualizadas, o modelo teórico e metodológico de Ball mostra-se importante para fazer uma análise do modo como são expressas as políticas educacionais nos documentos institucionais das universidades pesquisadas.

A Abordagem do Ciclo de Políticas tem sido empregada em diferentes países como um referencial analítico consistente para analisar a trajetória de políticas sociais educacionais. A esse respeito diz Ball:

O principal ponto que gostaria de destacar é o de que o ciclo de políticas é um método. É uma maneira de pesquisar e teorizar as políticas. Algumas pessoas o leram e interpretaram como se eu estivesse descrevendo políticas e os processos de elaborá-las. O ciclo de políticas não tem a intenção de ser uma descrição das políticas, é uma maneira de pensar as políticas e saber como elas são 'feitas'. (MAINARDES; MARCONDES, 2009, p. 304305).

Esse método se fundamenta na concepção de que a política, além de processos e consequências, é texto e também discurso, sendo que esses conceitos - texto e discurso - são complementares e estão imbricado um no outro. 
O referencial teórico-metodológico de Ball (1994) é composto por cinco Contextos (Influência, Produção do Texto, Prática, Resultados (efeitos) e o Contexto da Estratégia Política, sendo que nesta pesquisa utilizouse dois Contextos: o Contexto de Influência e o Contexto da Produção do Texto, mas, principalmente, a articulação entre eles, considerado como “[...] modelo conceitual para as trajetórias das políticas”. (BALL, 1994, p. 26).

O Contexto de Influência é onde as políticas se iniciam e onde são construídos os discursos políticos. Neste Contexto é que ocorrem as disputas feitas pelas pessoas e grupos de interesse que buscam adquirir apoio e legitimidade para as suas propostas, influenciando as finalidades das políticas. Ocorre, também, a elaboração dos conceitos e onde estes adquirem legitimidade, dando base para a construção da política. Além destes, estão envolvidos outros elementos, como as influências globais e internacionais que podem ocorrer através do fluxo de ideias, por meio de redes públicas e sociais que compreendem a circulação internacional de ideias denominado de processo de empréstimo de políticas, onde os grupos e indivíduos vendem suas soluções no mercado político e acadêmico e, também, o patrocínio e mesmo à imposição de certas soluções recomendadas por agências multilaterais como o Banco Mundial. Este, tem particular importância dado que as suas intenções só podem ser compreendidas como uma instância ideológica de promoção de um sistema mundial integrado com as linhas de mercado (BALL, 1998).

Ao lado do Banco Mundial, pode-se citar também a Organização para Cooperação e Desenvolvimento Econômico (OCDE), a UNESCO e o Fundo Monetário Internacional (FMI), pois essas agências exercem influência sobre o processo de criação de políticas nacionais. Tais influências, no entanto, necessitam ser sempre recontextualizadas e reinterpretadas (BALL, 2006).

O segundo Contexto denominado de Produção do Texto, é onde os textos políticos são produzidos. Este possui o que Ball e Bowe (1992) chamam de relação simbiótica com o contexto de influência, não sendo, no entanto, uma relação evidente ou simples. Enquanto o contexto de influência está relacionado a interesses e ideologias dogmáticas, os textos 
políticos estão articulados com a linguagem do interesse público, podendo assumir diferentes formas: texto, documentos, entrevista com autores de textos de políticas, entrevistas com aqueles para os quais tais textos foram escritos e distribuídos. Esses nem sempre são claros nem possuem uma coerência interna, sendo muitas vezes contraditórios (BALL; BOWE et al., 1992).

A respeito dos Contextos, é importante observar que estes estão inter-relacionados, não possuindo uma dimensão temporal ou sequencial e também não se constituem em etapas lineares. Diz Ball (2006, p. 51) que “[...] cada contexto consiste em uma série de arenas de ação e envolve lutas e compromissos. Eles são livremente acoplados e não há uma simples direção de fluxo de informação entre ele".

Segundo Mainardes (2006, p. 48) a Abordagem do Ciclo de Políticas, constitui-se num referencial analítico útil para a análise de programas e políticas educacionais "[...] pelo fato de que essa abordagem permite a análise crítica da trajetória de programas e políticas educacionais desde sua formulação inicial até a sua implementação no contexto da prática e seus e efeitos".

Para que essa análise fosse feita com mais profundidade na presente pesquisa, percebeu-se a necessidade da utilização de outros referenciais metodológicos para a análise documental e de conteúdo, utilizada em conjunto com o referencial teórico e metodológico da Abordagem do Ciclo de Políticas de Ball (1992; 1994). Após a constatação da existência de diferentes metodologias, considerou-se o Método de Análise Documental proposto por Cellard (2012) e o Método Comparado em Educação de Bereday (1972) como as mais adequadas, pois atendem ao propósito da pesquisa.

O método da análise documental proposto por Cellard (2012) ocorre em duas etapas: a análise preliminar e a análise propriamente dita. A análise preliminar abrange: o contexto; o autor ou autores; autenticidade e confiabilidade do texto; a natureza do texto; os conceitos-chave e a lógica interna do texto. Estas dimensões permitem, ao pesquisador, acessar o documento e empreender uma interpretação coerente, tendo em vista a temática ou seus questionamentos iniciais, não se constituindo num método rígido, mas interpretações que "[...] decorrem das escolhas do pes- 
quisador com relação ao problema e ao tema de sua investigação, bem como de suas preferências teóricas" (CELLARD, 2012, p. 314).

A primeira dimensão denominada contexto é primordial para o desenvolvimento das demais etapas, pois compreende o cenário social, cultural, econômico e político no qual uma documentação foi produzida e permite ao pesquisador "[...] apreender os esquemas conceituais de seu ou de seus autores, compreender sua reação, identificar as pessoas, grupos sociais, locais, fatos aos quais se faz alusão, etc.” (CELLARD, 2012, p. 299).

Na segunda dimensão - identificação do(s) autor (es) do documento - trata-se de identificar quem produziu o documento, as intenções pessoais ou institucionais de sua produção e o tipo de mediação que ocorre entre o relato e as falas dos atores, considerando a competência e a autoridade destes.

Já na terceira dimensão denominada verificação da autenticidade e da confiabilidade do documento, ressalta-se a importância de verificar a qualidade da informação contida no documento, bem como o motivo da preservação do mesmo e o tipo de relação entre o autor ou autores e o que eles descrevem.

Na quarta dimensão chamada natureza do texto, busca-se compreender o que o autor ou autores querem expressar ao escrever o texto, considerando o contexto e a temática do mesmo.

Na quinta dimensão - conceitos-chave e a lógica interna do texto se busca compreender o sentido dos termos empregados pelo autor ou autores do texto, delimitando adequadamente os sentidos das palavras e dos conceitos. Os conceitos-chave tomados na pesquisa estão de acordo com a definição de Fujita (2004). Essa autora os define como sendo "[...] uma representação do conteúdo significativo do texto”. (FUJITA, 2004, p.258).

Observamos que na pesquisa foram utilizadas quatro dimensões, o contexto, os autores do documento, a natureza do texto e os conceitoschave, que fazem parte da primeira etapa (análise preliminar) ${ }^{2}$. Essas dimensões foram aplicadas em todos os documentos, com especial ênfase no

\footnotetext{
2 Não será utilizada a dimensão denominada "autenticidade e confiabilidade do texto" por se tratar de documentos estudados, conhecidos e divulgados.
} 
uso da dimensão denominada conceitos-chave, constando da extração de excertos dos documentos, possibilitando, assim, a construção de uma unidade de sentido em cada um dos grupos de documentos estudados. Esses conceitos-chave, segundo Ludke e André (1986), também podem ser denominados categorias de análise. Ainda segundo esses autores, em relação à construção de categorias, vale lembrar que:

[...] Não existem normas fixas nem procedimentos padronizados para a criação de categorias, mas acredita-se que um quadro teórico consistente pode auxiliar uma seleção inicial mais segura e relevante. [...]. Em primeiro lugar faça o exame do material procurando encontrar os aspectos relevantes. (LUDKE; ANDRE, 1986, p. 43).

A segunda etapa do método, denominada "análise" (CELLARD, 2012, p. 303) tem como objetivo produzir ou reelaborar conhecimentos e criar novas formas de compreender os fenômenos. O pesquisador poderá realizar uma interpretação coerente considerando a temática ou o questionamento inicial. Da mesma forma que o procedimento que o levou até a análise, a abordagem permanece tanto indutiva quanto dedutiva, podendo as duas conjugar-se. As escolhas de pistas documentais apresentadas, no leque que é oferecido ao pesquisador, devem ser feitas à luz do questionamento e do propósito inicial da pesquisa. $\mathrm{O}$ pesquisador deve interpretar os documentos, sintetizar as informações, determinar tendências e, na medida do possível, fazer a inferência. Nesta pesquisa a etapa chamada por Cellard (2012) 'análise', é denominada de 'Análise Comparativa', sendo utilizada especificamente nos documentos institucionais das Universidades pesquisadas.

As combinações possíveis entre os diferentes elementos contidos nas fontes estabelecem-se em relação ao contexto, à problemática ou ao quadro teórico, mas também, deve-se admiti-lo, em função da própria personalidade do pesquisador, de sua posição teórica ou ideológica. (CELLARD, 2012, p. 304).

Quanto ao método de Educação Comparada de Bereday, diz Bray (2005, p. 249), que o modelo continua a ser útil, mesmo tendo passado várias décadas depois que foi apresentado pela primeira vez, "[...] porque 
sublinha o valor da sistematização e da pergunta equilibrada. O modelo enfatiza, além disso, a importância da educação na visualização dos fenômenos dentro de seus contextos mais amplos”.

A aplicação deste método, na pesquisa, fundamenta-se também, em Lijphart (1971). Segundo esse autor, desde os começos da década de 1970, a comparação se estabeleceu firmemente como um procedimento analítico central na ciência política, com as cátedras de Política Comparada apresentando o método comparativo como um traço deste campo de estudos.

O método comparativo é um instrumento apropriado em situações nas quais o número de casos a serem estudados é pequeno para permitir a utilização da análise estatística. Deste modo, a comparação se apresenta como uma estratégia analítica com fins não somente descritivos, mas também explicativos, um procedimento orientado para comprovar as hipóteses. (LIJPHART, 1971, p. 684-685, tradução nossa).

Ainda em relação ao Método Comparado em Educação, concordamos com Torres (2013, p.53) quando afirma que o Método: "Al ser una alternativa metodologica, no puede en ningún momento dictar normas o leyes a seguir. Si así fuera, dejaría de comprender que cada país, al igual que cada persona, es única e irrepetible" (TORRES, 2013, p. 53). Ou seja, o mesmo não é normativo e não prescreve regras para o bom andamento dos sistemas educativos, mas busca, unicamente, compreender o que se faz e porque se faz desta maneira

Considerando essas perspectivas e concepções é que o Método Comparado em Educação de Bereday (1972) foi utilizado na pesquisa. O propósito é dar maior consistência a 'análise', segunda etapa da proposta de Cellard (2012), pois no método desenvolvido por esse autor não está prevista a análise comparativa, de fundamental importância na pesquisa, já que a mesma aborda duas universidades localizadas em diferentes contextos.

Bereday (1972, p. 37) classifica o seu método como "comparativo sistemático" e que as "divisões convencionais" apresentadas são "[...] apenas uma variante atual de todas as classificações possíveis”. O método se constitui de quatro estágios: descrição, interpretação, justaposição e comparação, sendo que na pesquisa foi utilizado somente o último estágio, a com- 
paração, pois os estágios anteriores (descrição, interpretação e justaposição) já estão contemplados na primeira etapa do Método de Análise Documental de Cellard (2012), a análise preliminar.

\section{O desenvolvimento da pesquisa: fases diferentes e complementares}

A pesquisa foi desenvolvida em seis fases diferentes e complementares. Na primeira fase, abordou-se os principais documentos institucionais da Unisinos (o Estatuto 2014 e o PDI-PPI 2006-2011) e da Javeriana (o Estatuto 2013, a PU-2007-2016 e a PE-1992-2015). A análise desses documentos, indicava, que eles possuíam na sua redação dois conjuntos de termos significativos diferentes: um conjunto de termos próprios do pensamento humanista social cristão e, outro, do pensamento econômico neoliberal. Essa constatação fez com que se realizasse uma ampla busca bibliográfica considerando esses dois temas e a sua relação com a Educação Superior e, a confrontar os documentos encontrados com os documentos institucionais da Unisinos e da Javeriana. A partir da comparação e do entrecruzamento dos textos, constatou-se que esses últimos foram subsidiados na sua elaboração, se inspirando e, ao mesmo tempo, sendo influenciados por documentos relacionados ao humanismo social cristão e documentos relacionados às ideias do neoliberalismo econômico, formando cinco corpora documentais distintos.

O primeiro e o segundo corpus documental são portadores dos princípios e valores do humanismo social cristão. O primeiro é formado pelos documentos do Concílio e do Pós-Concílio Vaticano II: a Constituição Pastoral Gaudium et Spes; a Encíclica Populorum Progressio (1965); a Carta Apostólica Octogesima Adveniens (1971) e a Constituição Apostólica Ex Corde Ecclesiae (1990). O segundo é constituído por documentos corporativos da Companhia de Jesus, dentre os quais estão: os Exercícios Espirituais (1548); as Constituições (1558); os documentos elaborados pela Companhia que abordam a área educacional: Características da Educação da Companhia de Jesus (1987), o Decreto 17 da Congregação 
Geral XXXIV da Companhia de Jesus (1995); os documentos elaborados pela Associação das Universidades confiadas à Companhia de Jesus na América Latina (AUSJAL): Desafios da América Latina e Proposta Educativa AUSJAL (1995); o Plano Estratégico da AUSJAL (2001-2010) e, por último, o documento elaborado pela Conferência dos Provinciais da América Latina (CPAL): Projeto Educativo Comum (PEC-2005).

O terceiro corpus documental, é constituído por alguns documentos portadores dos princípios e ideias neoliberais elaborados pela UNESCO e pelo Banco Mundial: a Conferencia Mundial sobre la Educación Superior: Informe Final (1998); o documento elaborado pelas duas entidades em conjunto: La Educación Superior en los países en desarrollo: peligros y promesas (2000); o documento do Banco Mundial denominado Construir Sociedades de Conocimiento: nuevos desafios para a la educación Terciaria (2003).

O quarto corpus documental é formado por alguns documentos do sistema educacional brasileiro (Leis e Planos Educacionais)3: o Plano Nacional de Educação (PNE) 2001-2010; do Sistema Nacional de Avaliação da Educação Superior (SINAES) 2004; da Lei de Inovação Tecnológica (2004); do Plano Nacional de Pós-graduação 2005-2010.

O quinto corpus é constituído por alguns documentos do sistema educacional Colombiano: o Plan Nacional Decenal de Educación (20062016) e o Plan Sectorial (2006-2010): Revolución Educativa.

A partir desse levantamento, na segunda fase da pesquisa foi abordado o primeiro corpus documental, mostrando o modo como aparece o humanismo social cristão. Em cada um dos documentos utilizou-se a primeira parte (análise preliminar) do método de Cellard (2012), considerando-se quatro dimensões (contexto; autor ou autores; natureza do texto; e conceitos-chave). Na dimensão denominada conceitos-chave, destacou-se excertos (termos e frases) de cada documento, relacionadas ao humanismo social cristão. Os excertos (termos e frases) funcionaram

3 O termo 'documentos do sistema educacional' abarca tanto as Leis, Normas, Regulamentos, Decretos, quanto os Planos Educacionais, lineamentos e outros documentos lançados pelos respectivos governos da Colômbia e do Brasil, sejam os ministérios da educação, ou outras entidades a ele vinculadas ou subordinadas. 
como um fio condutor, possibilitando a elaboração de um texto com unidade de sentido e coerência, assim como, permitiu a elaboração de quadros com palavras e frases, que apareciam com mais frequência nos respectivos documentos. Esses termos, advindos dos excertos e relacionados em quadros, permitiu considerar o próprio termo 'humanismo social cristão' como um 'termo-síntese'4 dos termos citados. Nessa fase, não foi utilizada a segunda etapa (análise) da metodologia de Cellard (2012), pois não se trata de analisar criticamente os documentos, mas apresentar como os mesmos são portadores do humanismo social cristão, que influenciará/inspirará, subsidiando na elaboração dos documentos institucionais da Unisinos e da Javeriana. Os documentos que compõem esse corpus documental são considerados, na pesquisa, como Contexto de Influência, segundo a proposta de Ball (1994).

$\mathrm{Na}$ terceira fase analisou-se a maneira como nos documentos institucionais da Unisinos (Estatuto 2014; PDI-PPI 2006-2011) e da Javeriana (Estatuto 2013, PU 2007-2016; PE 1992-2015), está presente o humanismo social cristão. Na abordagem desses documentos considerou-se as duas etapas do método de Cellard (2012): a etapa da análise preliminar e a etapa da análise, sendo que na etapa da análise preliminar, utilizaram-se os mesmos procedimentos da fase anterior. Os excertos, (palavras e frases) e a elaboração dos quadros, mostraram, um conjunto de termos iguais, ou, de alguma forma, relacionados ao humanismo social cristão (termosíntese), presentes nos documentos do Concílio e do Pós-Concílio Vaticano II e, nos documentos corporativos da Companhia de Jesus, citados anteriormente.

Na etapa da análise tomou-se o referencial teórico de Ball (1994) e o método comparado em educação de Bereday (1972), considerando-se os dados extraídos na etapa da análise preliminar dos documentos do Concílio e do pós-concílio Vaticano II e, os dados dos documentos corporativos

\footnotetext{
4 A inspiração para o uso do 'termo-síntese', vem de Gilles Deleuze ([1953] 2001, p.184 e 122). O autor o utiliza na sua obra Empirismo e subjetividade, para explicar composições de natureza diversa. Nessa perspectiva é que consideramos o termo humanismo social cristão como um termo-síntese, pois o mesmo reúne e expressa em si, uma ampla variedade de termos relacionados ao humanismo, cristianismo e as questões sociais.
} 
da Companhia de Jesus, confrontando os mesmos com os documentos institucionais das Universidades pesquisadas. O referencial analítico comparativo, ou o tertium comparationis do método de Bereday (1972), empregado na análise comparativa foi a própria expressão humanismo social cristão (termo síntese), devido à vinculação/pertença das duas Universidades a Companhia de Jesus. Salientamos que esses documentos fazem parte do Contexto de Elaboração do Texto da Abordagem do Ciclo de Políticas de Ball (1994).

Na quarta fase da pesquisa, abordou-se o neoliberalismo econômico e os organismos internacionais na perspectiva da relação desses com a Educação Superior. Essa fase constou de dois momentos: no primeiro, apresentou-se o modelo neoliberal abordando-se sua origem, estruturação, conceitos principais e manifestações, assim como, a sua relação enquanto influencia/subsidio na elaboração das políticas educacionais para a Educação Superior na América Latina. Considerou-se, especificamente, três das manifestações ou fatos decorrentes e, ao mesmo tempo, constitutivos do neoliberalismo, que mais dizem respeito a pesquisa (a reforma do Estado, a globalização e a sociedade do conhecimento).

Num segundo momento, tomou-se os documentos direcionados à Educação Superior, elaborados por dois dos principais organismos internacionais de incentivo e fomento à educação: a UNESCO e o Banco Mundial: a Conferencia Mundial sobre la Educación Superior: Informe Final (1998); o documento elaborado pelas duas entidades em conjunto: $L a$ Educación Superior en los países en desarrollo: peligros y promesas (2000); o documento do Banco Mundial denominado Construir Sociedades de Conocimiento: nuevos desafios para a la educación Terciaria (2003).

Nesses documentos utilizou-se a primeira etapa (análise preliminar) do método proposto por Cellard (2012). Na dimensão denominada conceitos-chave, destacou-se excertos dos documentos (termos e frases) relacionados aos princípios neoliberais, funcionando como um fio condutor, possibilitando a elaboração de um texto com unidade de sentido e coerência, assim como, a elaborado de quadros com esses conceitos-chave. Esse conjunto de termos, permitiu, a partir dos excertos (termos e frases), e dos 
quadros elaborados com os mesmos, elaborar os 'termos-síntese': sociedade do conhecimento, qualidade da educação, excelência acadêmica, gestão, inovação, avaliação e tecnociência. Esses termos manifestam as ideias neoliberais, funcionando como orientação, recomendação ou normatização para as instituições de Educação Superior. Esses documentos são considerados, na pesquisa, fazendo parte do Contexto de Influência da Abordagem do Ciclo de Políticas de Ball (1994).

A análise dos respectivos documentos mostrou que os mesmos continham orientações para a elaboração de políticas e programas educacionais direcionadas à Educação Superior, e que esses exerceram influência nos governos dos países abarcados pela pesquisa no sentido de elaborarem leis, programas e planos direcionados à Educação Superior.

Considerando esse fato, na quinta fase da pesquisa analisou-se a maneira como essas ideias e orientações se manifestam em alguns documentos dos respectivos sistemas educacionais relacionados à Educação Superior. Em relação ao Brasil, os documentos abordados foram: o Plano Nacional de Educação (PNE) 2001-2010; o Sistema Nacional de Avaliação da Educação Superior (SINAES) 2004; a Lei de Inovação Tecnológica; o Plano Nacional de Pós-graduação 2005-2010. Quanto à Colômbia utilizou-se os seguintes documentos: o Plan Nacional Decenal de Educación (2006-2016) e o Plan Sectorial (2006-2010): Revolución Educativa.

Foram utilizados nos respectivos documentos a primeira parte do método de Cellard (2012) - a análise preliminar - se empregando os mesmos procedimentos das fases anteriores, sendo aplicadas às quatro dimensões que a compõem, considerando-se, especialmente, a dimensão denominada conceitos-chave, destacando-se excertos (termos e frases) que funcionaram como fio condutor, dando uma unidade de sentido e coerência ao texto e se elaborando quadros com as mesmas. Os excertos e os quadros elaborados com as palavras e frases dos documentos do sistema educacional colombiano e brasileiro, mostraram que nos mesmos, há um conjunto de termos iguais ou, de alguma forma, relacionados aos princípios neoliberais presentes nos documentos elaborados pela UNESCO e pelo Banco Mundial. Compreende-se que esse conjunto de termos pode 
ser sintetizado nos mesmos 'termos-síntese', (sociedade do conhecimento, qualidade da educação, excelência acadêmica, gestão, inovação, avaliação e tecnociência), referentes aos documentos dos organismos internacionais relacionados com a Educação Superior, pois os mesmos manifestam os pressupostos neoliberais, funcionando como orientação, recomendação ou normatização para as instituições de Educação Superior.

Na sexta fase da pesquisa, abordou-se os documentos da Unisinos (Estatuto 2014, o PDI, PPI 2006-2011) e, os documentos da Javeriana (Estatuto 2013, a PU 2007-2016 e o PE-1992-2015, na perspectiva do Contexto de Elaboração do Texto de Ball (1994), mostrando como se apresentam nesses documentos institucionais as influências/determinações/condicionamentos dos documentos do sistema educacional colombiano e brasileiro, assim como, dos documentos emitidos pelos organismos multilaterais (UNESCO e Banco Mundial), portadores de ideias e princípios do neoliberalismo econômico. Foram utilizadas as duas etapas propostas por Cellard (2012), a etapa da análise preliminar e a etapa da análise. Na etapa da análise preliminar (na dimensão denominada conceitos-chave), foram destacados excertos dos documentos (termos e frases) e foram elaborados quadros com as mesmas, sendo que os excertos funcionaram como um fio condutor, construindo uma unidade de sentido e coerência, comprovando que esses documentos, na sua elaboração, receberam influências/orientações/determinações dos documentos dos sistemas educacionais dos respectivos países onde estão localizadas as duas universidades. Os excertos e os quadros com os termos e frases permitiram, a exemplo das duas fases anteriores, chegar-se aos 'termos-síntese' (sociedade do conhecimento, qualidade da educação, excelência acadêmica, gestão, inovação, avaliação e tecnociência), que manifestam os pressupostos neoliberais.

Em seguida, foi utilizada a segunda parte do método de Cellard (2012), a análise. Essa etapa se caracterizou como análise comparativa, considerando o referencial teórico de Ball (1994) e o método comparado em educação de Bereday (1972). Considerou-se, na respectiva análise, os dados extraídos na etapa da análise preliminar (termos e frases), que mostram que esses documentos foram subsidiados/influenciados pelos 
documentos do sistema educacional brasileiro e colombiano. O referencial analítico comparativo, ou o tertium comparationis do método de Bereday (1972), empregado na respectiva análise comparativa é o conjunto de cinco expressões, os 'termos-síntese' (sociedade do conhecimento, qualidade da educação, inovação, avaliação e tecnociência), presentes nos respectivos documentos.

\section{Resultados e discussão}

Dentre os resultados da pesquisa apresentamos os mais significativos, que são os seguintes:

1 - Os documentos institucionais das universidades pesquisadas foram subsidiados na sua elaboração, inspirando-se e, ao mesmo tempo, recebendo influências, provenientes de uma complexa mescla de orientações e regulamentos presentes em documentos emitidos, tanto pelas instituições às quais as respectivas universidades estão vinculadas, - a Igreja Católica e a Companhia de Jesus, - quanto pelos documentos emitidos pelos governos dos países onde essas se localizam, subsidiados, na sua elaboração, por orientações provenientes dos documentos dos organismos internacionais, UNESCO e Banco Mundial, portadores da lógica neoliberal. Esse conjunto de documentos, somados às opções decorrentes da identidade, missão e visão de cada IES, confluem/influenciam na elaboração dos seus documentos institucionais. No entanto, a elaboração dos respectivos documentos não ocorre por pura inspiração/influência dos documentos emitidos pelas instituições e governos, (nível macro), através de um processo de simples acomodação ou assimilação, sendo recontextualizadas, reelaboradas e ressignificadas a nível institucional, onde se entrecruzam diferentes fatores e interesses relacionados à própria identidade, missão e visão de cada IES (nível micro).

2 - Nota-se que tanto o Estatuto da Javeriana quanto o da Unisinos fornecem rigorosamente as informações específicas sobre as respectivas instituições solicitadas pelos órgãos governamentais. A redação e o conteúdo da maior parte dos respectivos documentos, no entanto, é muito dife- 
rente. Enquanto o Estatuto da Javeriana possui, um conjunto acentuado de termos que identificam a Universidade com os princípios do humanismo social cristão, e nenhum termo que implique um possível alinhamento com as ideias e os princípios neoliberais, no Estatuto da Unisinos, ocorre o contrário, correndo poucas referências ao humanismo social cristão, e vários termos característicos ou que se assemelham as ideias neoliberais.

3 - Em relação ao PDI da Unisinos e a PU da Javeriana, ambos são significativamente diferentes no que diz respeito à presença de termos que expressam os princípios humanistas e de termos próprios do neoliberalismo econômico. Se por um lado, no PDI da Unisinos há termos que expressam os princípios humanistas que fundamentam a existência e as ações da universidade, especialmente, quando apresenta sua Identidade e os Valores institucionais, por outro lado, ao abordar a experiência de Planejamento Estratégico da Universidade, as Perspectivas para o Período 2006-2010, as Diretrizes Pedagógicas Institucionais e as Propostas e Iniciativas para o Período 2006-2011, se utiliza um conjunto amplo de termos que se assemelham aos princípios neoliberais. Na PU da Javeriana, por sua vez, percebem-se muitos termos similares aos princípios do neoliberalismo econômico, ocorrendo, minimante, termos próprios ou que se referem de alguma forma ao humanismo social cristão. De forma semelhante ocorre no PPI da Unisinos 5, no qual se faz referência de forma bastante sucinta ao fato de que o mesmo segue os princípios da Pedagogia Inaciana. Diferentemente, ocorre no PE da Javeriana, cuja elaboração considera amplamente, os princípios do humanismo social cristão.

4 - Um fator importante é a questão da autonomia universitária na elaboração dos respectivos documentos institucionais. A pesquisa mostrou ser um tema de desdobramentos complexos, com evidentes implicações na elaboração dos Planos e Projetos Institucionais, muito especialmente no caso brasileiro. Isso ocorre devido as significativas diferenças na compreensão e aplicação das leis que tratam da autonomia universitária por parte dos governos brasileiro e colombiano. Na Colômbia há, por parte das instituições governamentais, um maior respeito à autonomia das IES na elabo-

5 Apresentado como Diretrizes Pedagógicas Institucionais. 
ração dos seus Projetos e Planos, considerando-se, por exemplo, a história da instituição, a sua presença na sociedade e o seu envolvimento com a mesma. O mesmo se passa com relação à Avaliação das IES. Na Colômbia a avaliação ocorre, para efeito de reconhecimento legal das condições mínimas de funcionamento, num processo denominado Acreditación, sendo posteriormente, de caráter voluntário por parte das IES ${ }^{6}$. Diferentemente ocorre no Brasil, onde a autonomia das IES é controlada de forma intensa pelo governo, impactando diretamente na elaboração dos respectivos Planos e Projetos. Dependendo da lei, norma, ou regulamento, simplesmente não há recontextualização, mas puro e simples acatamento por parte das IES. Percebe-se que a autonomia universitária, tanto na Colômbia quanto no Brasil é um tema que na prática é cercado de ambiguidades. Ocorre que as IES estão localizadas dentro dos sistemas sociais vigentes e acabam tendo que a ele se submeter, considerando as exigências das próprias leis elaboradas pelos governos, influenciadas na sua elaboração pelos princípios neoliberais provenientes de diversos documentos elaborados pelos organismos internacionais, fazendo com que IES se enquadrem numa perspectiva de padrão empresarial-organizativo-produtivo.

5 - Mesmo considerando as limitações impostas à autonomia universitária provenientes das leis dos governos, mais intensas no caso do Brasil que na Colômbia, a pesquisa mostra que as respectivas IES fazem as suas próprias opções, elaborando os seus Planos e Projetos Institucionais, de acordo com a sua identidade, missão e visão em relação às questões tanto administrativas, quanto didático-científicas e de gestão dos recursos humanos, patrimoniais, econômico-financeiros e materiais, culturais e de assistência social, religiosos e socioambientais e, outros desdobramentos decorrentes dessas áreas. Constata-se que as respectivas IES buscam, com grande esforço manter o que denominamos de 'fidelidade criativa aos princípios institucionais', que se traduz em adaptar/recontextualizar os

\footnotetext{
6 Importante observar que, as IES colombianas acabam por aceitar as regras para a Acreditación propostas pelo governo, pois esse é um reconhecimento 'oficial' da qualidade das IES, favorecendo a concessão de recursos financeiros, e fornecendo uma repercussão social positiva, o que favorece em muitos aspectos as IES.
} 
princípios humanísticos herdados desde a criação da Companhia de Jesus, aos novos contextos históricos, políticos sociais e econômicos.

6 - Algo que impacta diretamente na elaboração dos Planos e Projetos dessas IES são as demandas e necessidades impostas pelo próprio mercado, numa sociedade do consumo, movida pela economia da inovação nas áreas de tecnologias de informação, alimentação, lazer, saúde, transporte, segurança, etc. Isto, faz com que essas IES entrem, necessariamente, num novo padrão técnico econômico de crescente intensidade e complexidade da produção de conhecimentos desenvolvidos e, de acelerada incorporação de conhecimentos nos bens e serviços produzidos e comercializados. No caso da Javeriana, isso se percebe pelos cursos oferecidos nos diversos Institutos e pela prestação de Consultorias, Serviços e Assessoria altamente qualificadas para empresas. No caso da Unisinos, é perceptível nos cursos de cunho tecnológicos e na prestação de serviços e investigação oferecidos pelos Institutos Tecnológicos, na prestação de Consultorias, Serviços e Assessoria da própria Universidade e no Parque Tecnológico com a presença de empresas, prestando diferentes serviços altamente especializados e qualificados.

\section{Considerações finais}

No século XVI, no auge do poliforme fenômeno do Renascimento, diante do embate de diferentes e variadas concepções, pensamentos e compreensão de mundo e de pessoa humana, provenientes de diferentes e variadas fontes, a nascente área educacional da Companhia de Jesus assumiu os riscos e as consequências dos mesmos, tendo uma grande abertura de espírito para acolher o pensamento dos autores clássicos e dos autores que não eram cristãos, assumindo e colaborando na construção do pensamento humanista e o colocando como base fundamental de sua área educacional, elaborando um sistema de estudos denominado Ratio Studiorum que prosperou por um par de séculos. Atualmente, continuam os desafios. No entanto, estes possuem outra perspectiva ou di- 
mensão, tratando-se do diálogo e da aproximação entre o humanismo social cristão e o humanismo tecnocientífico.

Numa sociedade, onde a tecnociência se estende da microeletrônica à bioengenharia e consagra o triunfo do ideal cartesiano, com a razão matemática regendo de forma quase absoluta as várias dimensões da vida, entre as quais o espaço familiar humano e a economia política do conhecimento, e onde aparecem de maneira desafiadora, os problemas levantados pela produção, distribuição e assimilação do saber, bem como, os problemas surgidos pela produção, circulação e distribuição de bens e satisfação das necessidades, as IES da Companhia de Jesus buscam diagnosticar e interpretar de modo adequado a situação cultural de nosso tempo, do ponto de vista da razão que dialoga com a fé e que busca a justiça. Desta maneira, as criações da razão calculadora, passam a ser assumidas, gradualmente, considerando as contingencias históricas, em formas de vida integral para o ser humano, pois nestes tempos de forte expansão da razão tecnocientífica, muito vem se tirando da dignidade da pessoa humana.

Entendemos, que a pesquisa aporta duas contribuições significativas. A primeira delas, está relacionada ao fato de que a mesma fornece uma contribuição consistente para que as IES, sejam da Companhia de Jesus, sejam outras instituições de caráter confessional, religioso e comunitário, assim como as IES que não se estruturam sobre esses princípios, identifiquem os diferentes fatores que inspiraram/influenciaram na elaboração dos seus respectivos Planos e Projetos, oferecendo uma possibilidade para que essas vejam a si mesmas.

A segunda contribuição está no fato de que a pesquisa fornece uma plataforma que auxilia na elaboração de Planos, Projetos e mesmo Currículos Educacionais, permitindo considerar os elementos significativos que necessitam estar contidos nos mesmos. Esse dado é importante, pois permite construir, reformular ou manter a identidade de uma IES, especialmente das instituições de caráter confessional.

Quanto às limitações da pesquisa, destacamos o fato de não sido possível utilizar de maneira integral o método teórico metodológico de Stephen J. Ball (1994), a Abordagem do Ciclo de Políticas. Dos cinco con- 
textos considerados pelo autor, utilizamos somente dois (o Contexto de Influência e o Contexto de Elaboração do Texto).

\section{Referências}

ASSOCIAÇÃO DAS UNIVERSIDADES JESUÍTAS CONFIADAS A COMPANHIA DE JESUS NA AMÉRICA LATINA (AUSJAL). Desafíos de América Latina y propuesta educativa de AUSJAL. Bogotá: Secretaria Ejecutiva, 1995.

. Plano estratégico (2001-2005). Universidad Católica Andrés Bello, Publicaciones UCAB, Caracas, 2001.

BALL, Stephen J. Big policies/small world: an introduction to international perspectives in education policy. Comparative Education, London, v. 34, n. 2, p. 119-130, 1998.

. Education Policy and Social Class. The selected works of Stephen J. Ball. World Library of Educationalists series. London: Routledge, 2006.

. Global education Inc: new policy networks and the neoliberal imaginary. London: Routledge, 2012.

. Entrevista com Stephen J. Ball: Uma Análise de sua Contribuição para a Pesquisa em Política Educacional. Revista aape/epaa. Universidad de San Andrés y Arizona State University, vol. 24 n. 24, p. 1-18 fev. 2016.

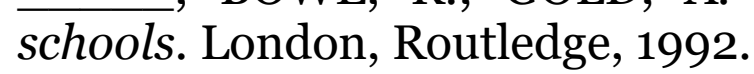

; BOWE, R.; GOLD, A. Reforming education and changing BANCO MUNDIAL. Construir sociedades de conocimiento: nuevos desafíos para a la educación terciaria. Washington: Banco Internacional de Reconstrucción y Fomento; Banco Mundial, 2003.

; UNESCO. La educación superior en los países en desarrollo: peligros y promesas. Grupo Especial Sobre Educación Superior y Sociedad. Santiago de Chile, 2000.

BARDIN, L. Análise de conteúdo. 4 ed. Lisboa: Edições 70, 2009.

BEREDAY, G. Z. F. Método comparado em educação. São Paulo: Nacional, 1972. 
BRASIL. Lei $n^{\circ}$ 10.172, de 9 de janeiro de 2001. Aprova o Plano Nacional de Educação e dá outras providências. Disponível em: Brasília, 2001. <http://www.planalto.gov.br/ccivil_03/leis/leis_2001/l10172.htm>. Acesso em: 13 nov. 2015.

. Ministério da Educação e Cultura. Comissão Especial da Avaliação da Educação Superior (CEA). Sistema Nacional de Avaliação da Educação Superior SINAES: Bases para uma nova proposta da Educação Superior. Comissão designada pelas Portarias MEC/SESu número 11 de 28 de abril de 2003 e número 19 de 27 de maio de 2003.

. Lei 10.973, de 2 de dezembro de 2004. Dispõe sobre incentivos à inovação e à pesquisa científica e tecnológica no ambiente produtivo e dá outras providências. Brasília, 2004e.

; CAPES. Plano Nacional de Pós-graduação (PNPG) 2005-2010. Brasília, 2004.

BRAY, M. Methodology and focus in comparative education. In: BRAY, M.; KOO, R. Education and society in Hong Kong and Macau: comparative perspectives on continuity and change. Hong Kong: Comparative Education Research Centre, 2005. p. 239-252.

CELLARD, A. A análise documental. In: POUPART, J. et al. (org.). $A$ pesquisa qualitativa: enfoques epistemológicos e metodológicos. $3^{\mathrm{a}}$ ed. Petrópolis: Vozes, 2012, p. 295-396.

COLOMBIA. Ministerio de Educación Nacional (MEN). Plan nacional decenal de educación 2006-2016. Lineamientos para la educación superior. Gerencia plan nacional de educación. Bogotá, 2006c.

. Ministerio de Educación Nacional (MEN). Plan sectorial (20062010): revolución educativa. Bogotá, 2006d.

COMPANHIA DE JESUS. Características da educação da Companhia de Jesus. Educação SJ, subsídios. São Paulo: Loyola, 1987.

. Constituições da Companhia de Jesus e Normas Complementa-

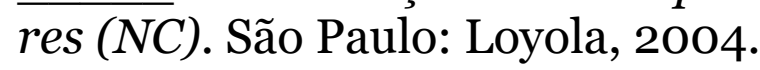

. Congregação Geral XXXIV - XV desde a restauração da Companhia. São Paulo: Loyola, 1995.

CONFERÊNCIA DOS PROVINCIAIS DA AMÉRICA LATINA (CPAL). Proyecto educativo común de la Compañía de Jesús en América Latina. São Paulo, Ed. Loyola, 2005.

CUNHA, L. A. Contribuição para a análise das interferências mercadológicas nos currículos escolares. Revista Brasileira de Educação, Rio de Janeiro, v. 16 n. 48, p. 591-607, set./dez. 2011.

DIDRIKSON, A. (org.). Tendencias de la educación superior en América Latina y el Caribe. Caracas: IESALC-UNESCO, 2008. 
DUARTE, T. A possibilidade da investigação a 3: reflexões sobre triangulação metodológica. CIES e-Working Papers, Lisboa, n. 6o, 2009.

FUJITA, M. S. L. A representação documentária de artigos científicos em educação especial: orientação aos autores para determinação de palavras-chave. Revista Brasileira de Educação Especial, Marília, v.10. n.3, v.10, n.3, p. 257-272, 2004.

JOÃO PAULO II, Papa (1920-2005). Constituição apostólica Ex Corde Ecclesiae sobre as Universidades Católicas. Roma, 1990.

KOMNINOS, N. Intelligent cities and globalization of innovation networks. London; New York: Routledge, 2008.

LIJPHART, A. Comparative politics and the comparative method. The American Political Science Review, [S.l.], v. 65, n. 3, p.682-693, 1971.

LINGENFELTER P. E. The knowledge economy: challenges and opportunities for american higher education. In: OBLINGER, D. G. Game changers: education and information technologies. Louisville, CO: EDUCAUSE, 2012.

LOYOLA, I., Santo. Exercícios Espirituais. São Paulo: Loyola, 2000.

LÜDKE, M.; ANDRÉ, M. E. D. A. Pesquisa em educação: abordagens qualitativas. São Paulo: EPU, 1986.

MAINARDES, J. Abordagem do Ciclo de Políticas: uma contribuição para a análise de políticas educacionais. Educação \& Sociedade, Campinas, v. 27, n. 94, p. 47-69, 2006.

MAINARDES, J.; MARCONDES, M. I. Entrevista com Stephen J. Ball: um diálogo sobre justiça social, pesquisa e política educacional. Educação \& Sociedade, Campinas, v. 30, n. 106, p. 303-318, 2009.

MIRANDA, M. Humanismo jesuítico e identidade da Europa, uma comunidade pedagógica europeia. Hvmanitas, Coimbra, v. 53, p. 83-111, 2001.

MOREIRA, S. V. Análise documental como método e como técnica. In: DUARTE, J.; BARROS, A. (org.). Métodos e técnicas de pesquisa em comunicação. 2 ed. São Paulo: Atlas, 2008, p. 267-279.

OLIVEIRA, M. M. Como fazer pesquisa qualitativa. Petrópolis, Vozes, 2007.

PAULO VI, Papa (1897-1978). Concílio Vaticano II. Constituição Pastoral Gaudium et spes, sobre a Igreja no Mundo Actual, Roma, 1965.

Roma, 1967.

. Concílio Vaticano II. Carta Encíclica, Populorum Progressio.

Roma, 1971.

. Concílio Vaticano II. Carta Encíclica, Octogésima Adveniens.

PONTIFICIA UNIVERSIDAD JAVERIANA. Estatutos. Bogotá, 2013. 
. Planeación Universitaria 2007-2017. Bogotá, 2007. . Proyecto educativo 1992. Bogotá, 1992.

TEODORO, A. A Educação em tempos de globalização neoliberal: os novos rumos de regulação das políticas educacionais. Brasília: Liber, 2011.

TORRES VILLALOBOS, E. M. Conjeturas en torno a la educación comparada. In: LEAL, M. A. N.; CAZALE, Z. N. (org.). Educación compara$d a$ : diversidad de intereses, diversidad de enfoques. México: Sociedad Mexicana de Educación Comparada: El Colegio de Tamaulipas, 2013, p. 47-62.

UNESCO. Declaración Mundial sobre la educación superior en el siglo XXI: visión y acción y marco de acción prioritaria para el cambio y el desarrollo de la educación superior. In: UNESCO: Conferencia Mundial sobre la Educación Superior: La Educación Superior en el Siglo XXI Visión y Acción, 1998, Paris. Anais eletrônicos... Paris, 1998, p. 19-36.

UNIVERSIDADE DO VALE DO RIO DOS SINOS (Unisinos). Estatutos. São Leopoldo, 2014.

- Missão e perspectivas 2006-2011, plano de desenvolvimento institucional Unisinos. São Leopoldo, 2006.

YOUNG, M. F. D. O futuro da educação em uma sociedade do conhecimento: a defesa radical de um currículo disciplinar. Cadernos de Educação, Pelotas, v. 38, p. 395-416, 2011. 